IJBPAS, December, Special Issue, 2021, 10(12): 615-623

ISSN: $2277-4998$

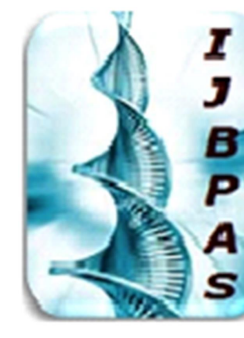

International Journal of Biology, Pharmacy and Allied Sciences (IJBPAS)

'A Bridge Betueen caboratory and QRendo'

WwW.ijbpas.com

\title{
SYZYGIUM CUMINI SEED HUSK POWDER AS AN EFFECTIVE PHOTOCATALYST FOR THE DEGRADATION OF HYDROXYNAPHTHOL BLUE DYE
}

\section{ASHOK V. BORHADE ${ }^{1, *}$, RANJANA P. BHADANE ${ }^{2}$ AND ABHISHEK S. KALE ${ }^{1}$}

1: Research Centre, Department of Chemistry, HPT Arts and RYK Science College, Nasik

$$
\text { 422005, India }
$$

2: Department of Chemistry, Nowrosjee Wadia College, Pune 411001, India Affiliated to Savitribai Phule Pune University, Pune

*Corresponding Author: Dr. Ashok V. Borhade; E Mail: ashokborhade2007@yahoo.co.in Received 20 ${ }^{\text {th }}$ Aug. 2021; Revised 24 ${ }^{\text {th }}$ Sept. 2021; Accepted 30 ${ }^{\text {th }}$ Oct. 2021; Available online $1^{\text {st }}$ Dec. 2021

https://doi.org/10.31032/IJBPAS/2021/10.12.2054

\begin{abstract}
The present study involves the degradation of Hydroxynaphthol blue dye using Syzygium Cumini seed husk powder as a green and cost effective photocatalyst. The Syzygium Cumini seed husk powder was characterized by various investigative techniques including Fourier Transform Infra-red (FT-IR) spectroscopy, Scanning Electron Microscopy (SEM), X-ray powder diffraction (XRD) and Brunauer-Emmett-Teller (BET). The Photocatalytic efficiency of Syzygium Cumini seed husk powder was investigated for the degradation of Hydroxynaphthol blue dye using visible light irradiation. The recyclability of Syzygium Cumini seed husk powder was also studied for the degradation and the results obtained have been discussed.
\end{abstract}

Keywords: Photocatalyst, Hydroxynaphthol blue dye, Recyclability.

Abbreviations: SCSHP = Syzygium Cumini seed husk powder

\section{INTRODUCTION}

Photocatalytic degradation has environmentally friendly features, cost become an important technology from effective and low energy utilization this many years for the mineralization of various organic pollutants. Because of its technology possesses great importance. For the wastewater treatment photocatalysis 
technique has attracted attention due to the generation of highly potent species such as $\mathrm{OH}$ and $\mathrm{O}_{2}$.

Varieties of hazardous pollutants from many industries are discharged into the aquatic bodies [1-3]. From last few decades dyes from textile and other commercial dyestuffs have been a focus of environmental remediation. Artificial dyes develop intense colour, highly toxic in nature and are harmful to the environment. Dyes possess high stability and are organic in nature. These dyes are not fully removed during washing process as the newly developed textile dyes alter aquatic life $[4,5]$.

The literature survey reveals that most of the work done using costly photocatalyst for photocatalytic degradation [6-14]. However there are no reports found in literature $[15,16]$ using efficient photocatalyst on mineralization of dyes using SCSHP. Further, it is also observed that most of these investigation deals with the synthesis and characterization of photocatalyst using various surfactant and complexing agents [17-21]. In the present study SCSHP [11$14]$ is used as a cost effective and efficient green photocatalyst for the degradation of Hydroxynaphthol blue dye under visible light irradiation. The product obtained was analysed by Fourier Transform Infrared
Spectroscopy (FT-IR), Brunauer-EmmettTeller (BET) and X-ray Diffraction (XRD) techniques.

\section{Preparation of SCSHP}

Syzygium Cumini used in the present study were collected from the local market of Nashik, Maharashtra, India. It was first cleaned and washed with tap water and then with distilled water several times to remove dust like impurities. The cleaned seed was oven dried at $60{ }^{\circ} \mathrm{C}$ for 24 $h$ and then husk of seed was removed. The Husk was powered, pulverized and stored in a plastic bottle for further use. No other chemical or physical treatments were used prior to experiments.

\section{Characterization}

SCSHP was characterized by appropriate physiochemical techniques including Fourier Transform Infra-red (FTIR) spectroscopy, Scanning Electron Microscopy (SEM), X-ray powder diffraction (XRD) and Brunauer-EmmettTeller (BET). IR adsorption study ( $\mathrm{KBr}$ Pellets) were performed on a Shimadzu, 8400-S FT-IR spectrometer in the range of (4000 to 400 ) $\mathrm{cm}^{-1}$. The phase purity of the product was performed by X-ray powder diffraction pattern using Rigaku Ultima IV copper instrument operating at $25 \mathrm{kV}$ and $25 \mathrm{~mA}$ using $\mathrm{K} \alpha$ radiation with wavelength $\lambda=0.154 \mathrm{~nm}$. Surface morphology was studied by scanning electron microscopy 
JEOL-JEM-6360A model equipment

JEOL-JEC-560 autocation coater.

\section{Photocatalysis}

In the present work photodegradation of Hydroxynaphthol blue dye was studied in presence of SCSHP as shown in Fig.1. Three kinds of experiments were performed. In the first experiment 50 ml $10 \mathrm{ppm}$ solution of Hydroxynaphthol blue dye was irradiated in a photoreactor using $1.0 \mathrm{gm}$ of SCSHP. The second experiment was carried out in absence of light. In third experiment only Hydroxynaphthol blue dye solution without catalyst was irradiated to visible light. The decrease in absorbance due to mineralization of dye was recorded on double beam UV-Visible spectrophotometer (systronics) after every $10 \mathrm{~min}$. For complete study on degradation of Hydroxynaphthol blue dye was performed by using $1.0 \mathrm{gm}$ of photocatalyst with 50 $\mathrm{ml}$ of $10 \mathrm{ppm}$ dye solution under constant environment.

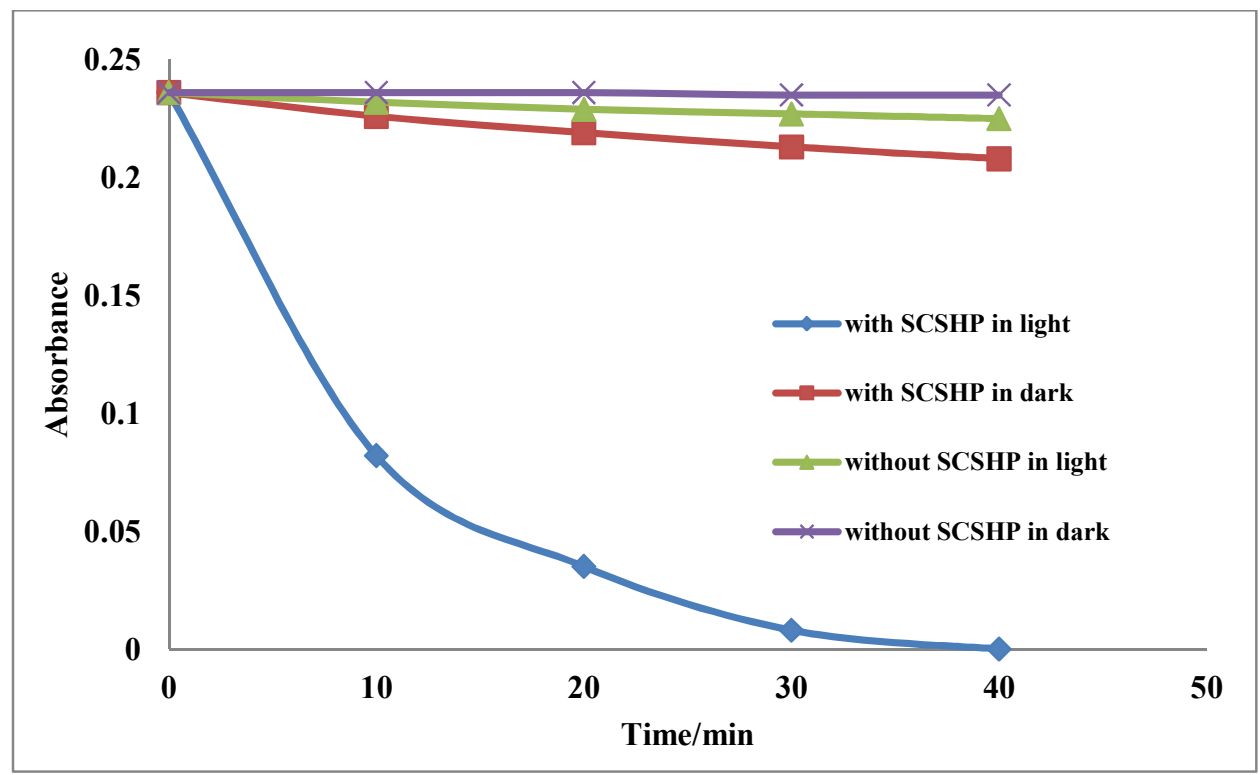

Fig. 1: Effect of catalyst and light irradiation on dye degradation using SCSHP

\section{RESULTS AND DISCUSSION}

\section{FT-IR Spectroscopy}

Figure 2 shows the infrared spectra of SCSHP and they showed that broad intense peaks at $3348.42 \mathrm{~cm}^{-1}$ is due to $\mathrm{C}-\mathrm{H}$ stretching.

The band at $1770.65 \mathrm{~cm}^{-1}$ is observed due to stretching vibration of
$\mathrm{C}=\mathrm{O}$ bond due to non-ionic carboxyl groups like $-\mathrm{COOH}$ or $-\mathrm{COOCH}_{3}$. Band appearing at $1608.63 \mathrm{~cm}^{-1}$ correspond to ionic hydroxyl group. The band at $405 \mathrm{~cm}^{-1}$ is due to IR bands.

\section{X-Ray Diffraction Studies (XRD)}

X-ray diffraction pattern of SCSHP is shown in Fig.3. The diffraction peaks are 
broad which indicating that the crystalline size is small. The (hkl) plane obtained from XRD pattern is shown in Fig.3.

\section{Scanning Electron Microscopy (SEM) with EDAX}

The surface morphological analysis of SCSHP is performed by SEM and is shown in Fig.4. A careful inspection shows that most of the crystals are big and collection of small particles. The agglomerate, non-adhesive, porous and irregular surface structure of adsorbent is distinctly observed in SEM image. The EDAX analysis (Fig.5) of SCSHP shows that it is composed of elements nitrogen $(\mathrm{N})$, calcium $(\mathrm{c})$, oxygen $(\mathrm{O})$, gold $(\mathrm{Au})$ and Carbon (C).

\section{Brunauer-Emmett-Teller (BET)}

$\begin{array}{llll}\text { Figure } & 6 & \text { depicts } & \mathrm{N}_{2}\end{array}$ adsorption/desorption isotherm for SCSHP. It shows that the $\mathrm{N}_{2}$ adsorption/desorption isotherm for AHSP satisfies IV $\mathrm{N}_{2}$ adsorption/desorption isotherm with $\mathrm{H} 1$ hysteresis. The surface area $\left(\mathrm{S}_{\mathrm{BET}}\right)$ estimated by this method was found to be $19.3 \mathrm{~m}^{2} / \mathrm{g}$.

\section{Effect of initial concentration}

The photocatalytic degradation of Hydroxynaphthol blue dye with various initial concentration in the range of 10 to 50 ppm was investigated as a function of visible light irradiation time with natural $\mathrm{pH}$ of suspension with the loading of 0.5 gm SCSHP in $100 \mathrm{ml}$ dye solution (Fig. 7). A careful inspection of Fig. 7 reveals that as the amount of Hydroxynaphthol blue dye increases the rate of degradation of the dye shows a smaller rise initially and then decreases gradually. It was mentioned that at lower amount of the dye, the photocatalytic reaction rate is nearly proportional to the dye concentration [22]. This is due to the fact that, when concentration of dye exceeds an optimum value, the light penetration decreases through solution thus decreasing, thus reducing the absorption of photon on SCSHP. Due to adsorption of dye on photoactive surface of catalyst there occurs a decrease in active sites. Present study reveals that, with increase in dye concentration upto certain range, the photocatalytic activity goes on decreasing. The lower range concentration of Hydroxynaphthol blue dye used in the present study is $10 \mathrm{ppm}$.

\section{Effect of amount of catalyst}

The amount of catalyst is an important factor for the study of photodegradation. Figure 8 shows variation of amount of catalyst $(0.2$ to $1.0 \mathrm{~g})$ at constant concentration of dye solution (10ppm) at neutral $\mathrm{pH}$. At low catalytic concentration, degradation rate is diminishing because less number of surface active sites are available. With rising dose 
of catalyst, the degradation efficiency increases. On Excess addition of photocatalyst the photons are get scattered from its surface and hence degradation rate diminishes. In this work, the minimum addition of SCSHP was found to be $0.6 \mathrm{gm}$ per $100 \mathrm{ml}$. Figure 8 reveals that the degradation of dye before and after exposure to the visible light and photocatalyst. It is observed that with increasing time of irradiation, the chromophoric absorption peak at $650 \mathrm{~nm}$ completely diminishes dark colorization of Hydroxynaphthol blue dye solution. The colour of solution (absorbance $650 \mathrm{~nm}$ ) decreased remarkably reaching a discoloration. Figure 8 confirms that within $120 \mathrm{~min}$ the absorbance reaches to minimum in presence of SCSHP.

\section{Recyclability of SCSHP for Degradation of Hydroxynaphthol blue Dye}

The recyclability for degradation of Hydroxynaphthol blue dye using SCSHP was checked over four runs (Fig.9). After every use, the photocatalyst was washed with distilled water and dried at $120^{\circ} \mathrm{C}$ and redistributed in fresh dye solution. The favourable reusability was showed by SCSHP after four times recycling. We did observe that during each run some extent of catalytic loss, this may cause decrease in degradation.

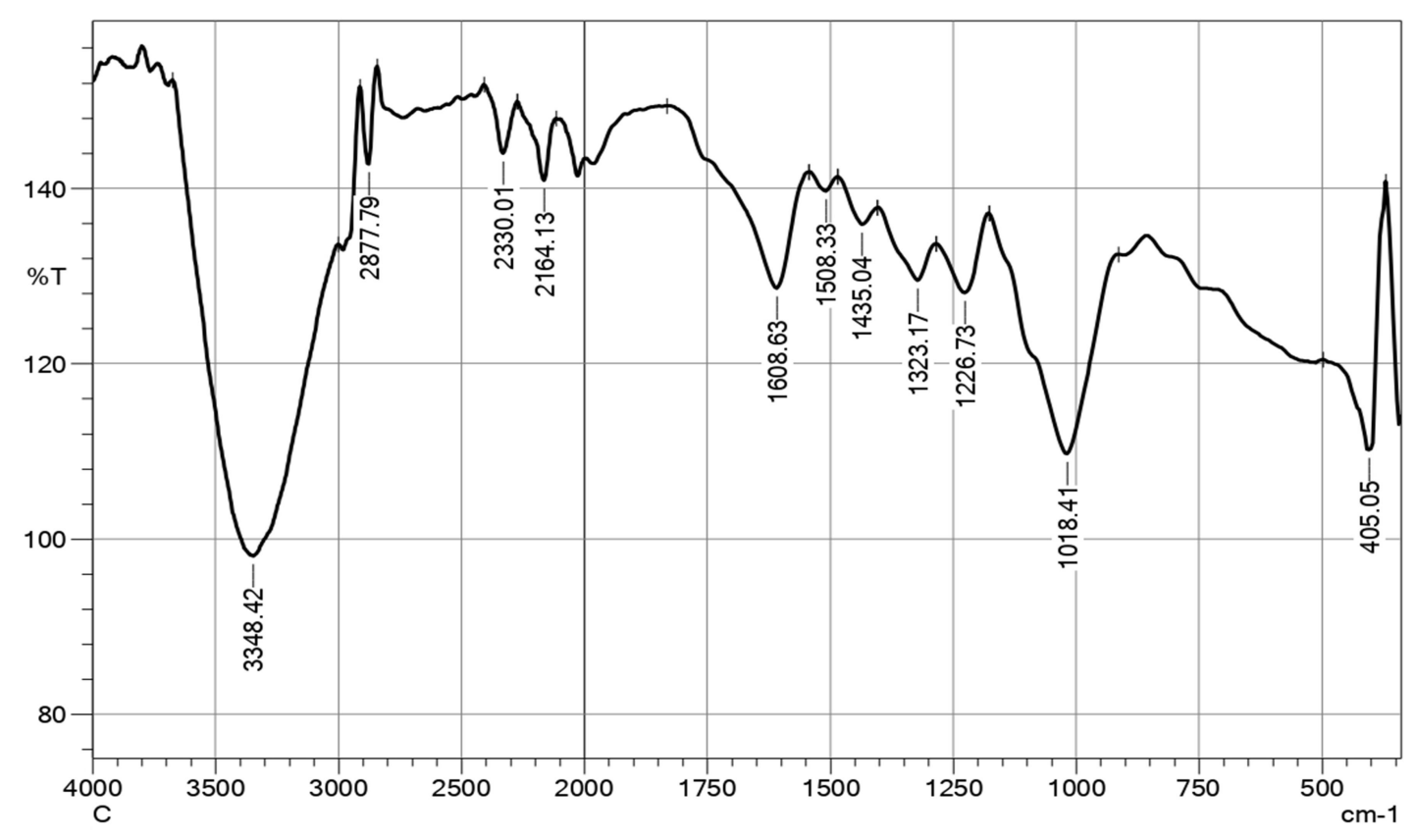

Fig. 2 FT-IR spectrum of SCSHP 


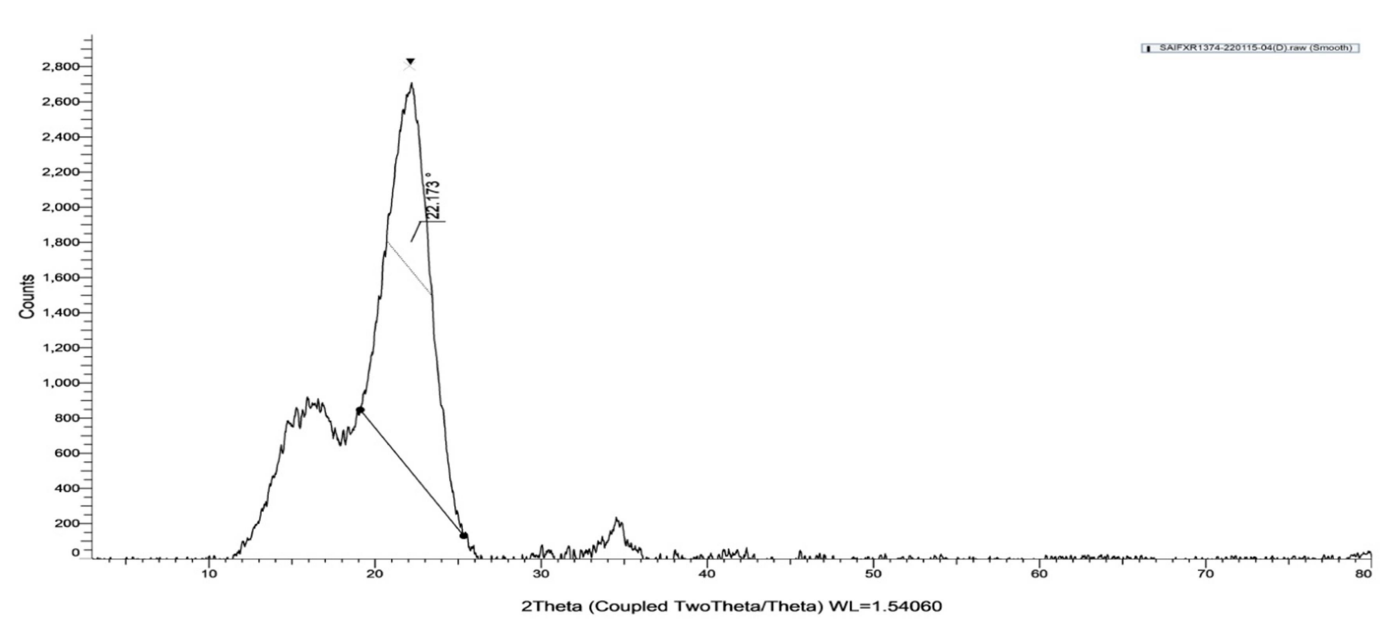

Fig. 3 XRD analysis of SCSHP

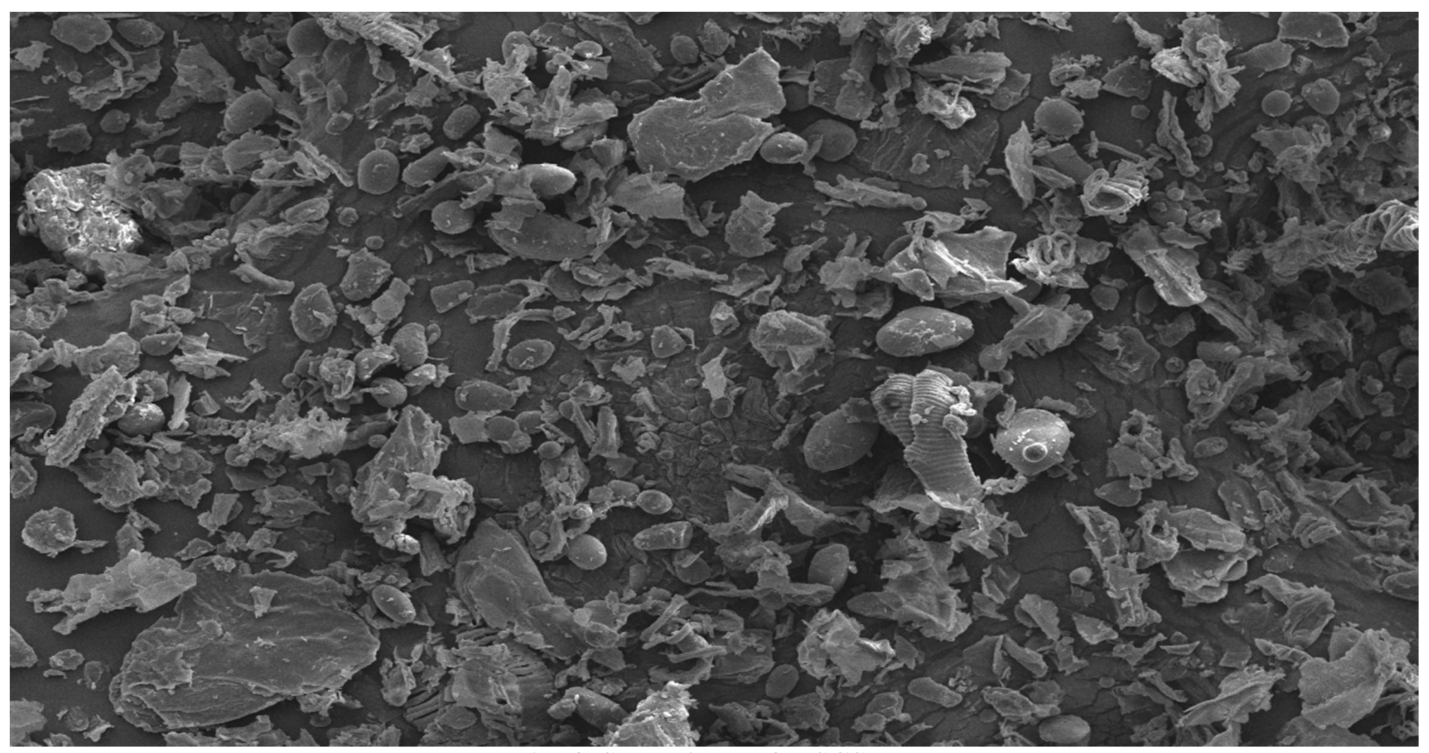

Fig. 4: SEM picture for SCSHP.

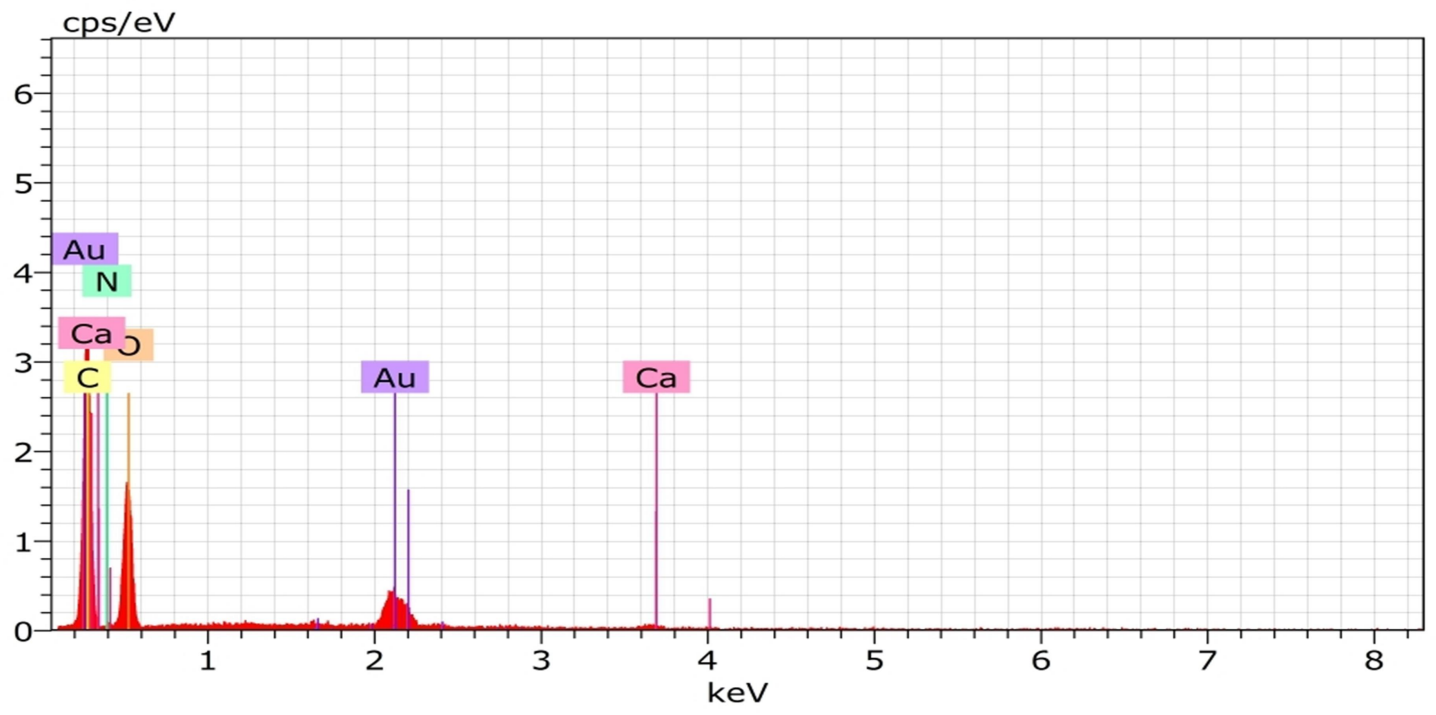

Fig. 5 EDAX analysis for SCSHP. 


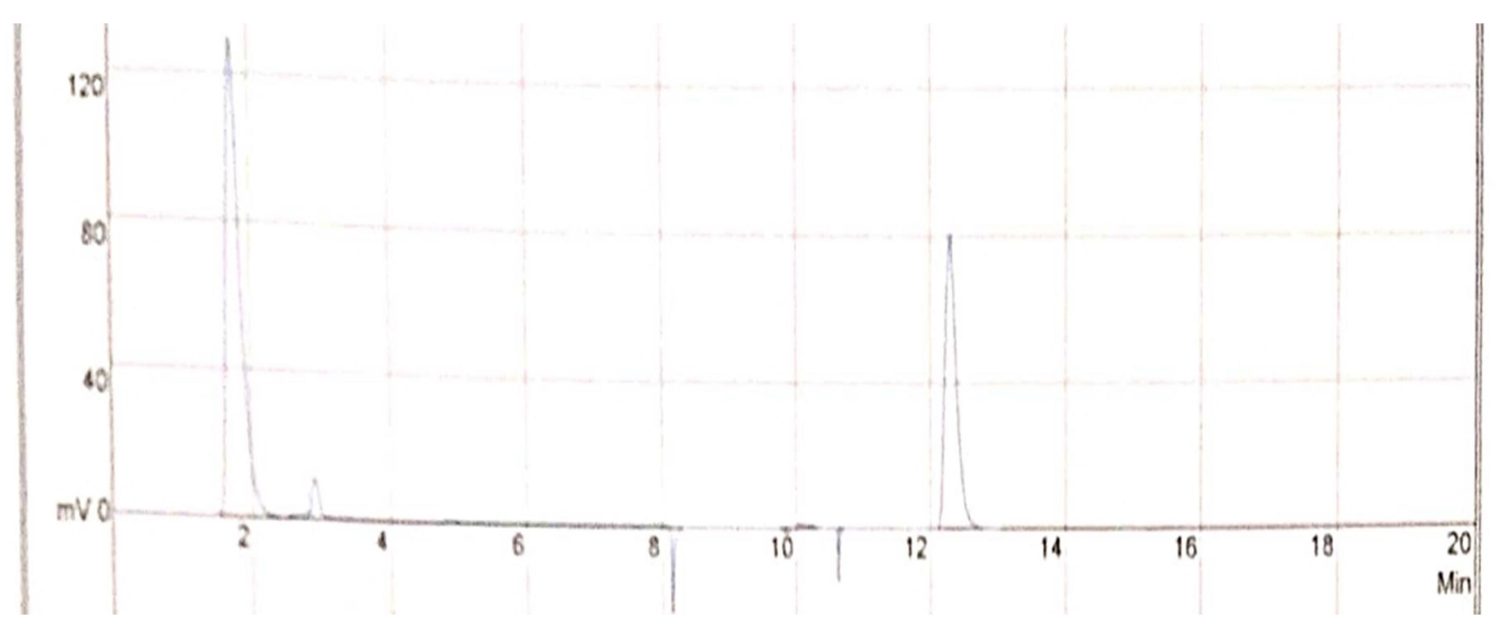

Fig. 6 BET Surface area of SCSHP.

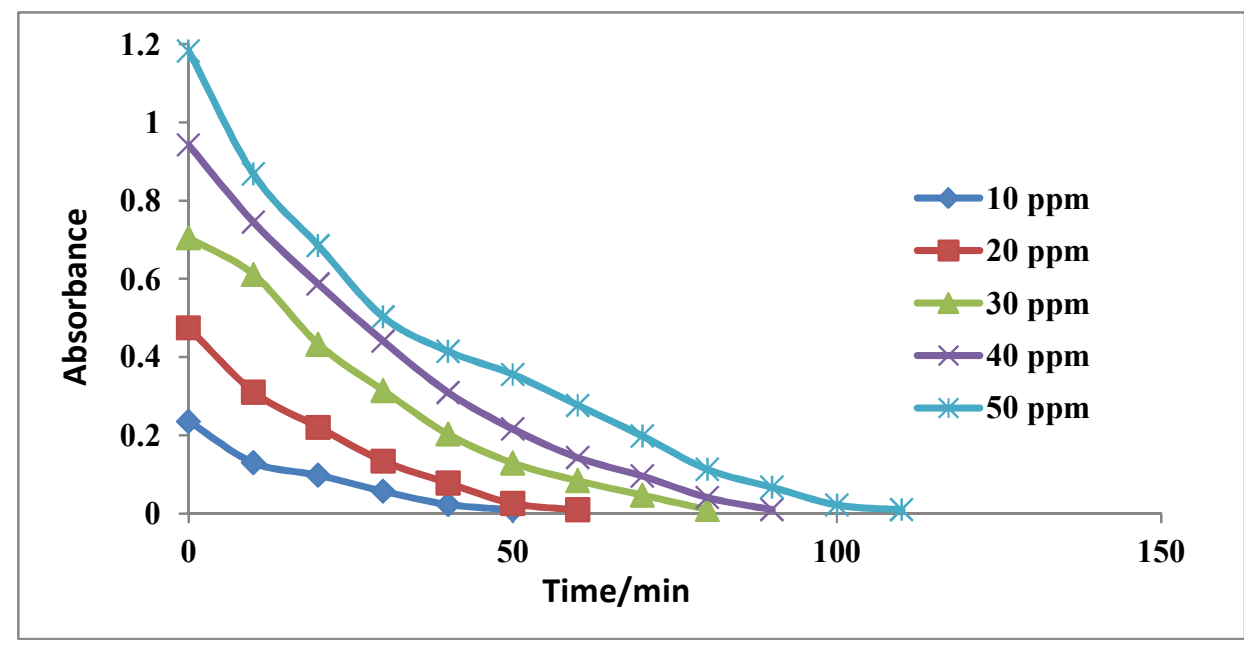

Fig. 7 Effect of initial concentration on SCSHP

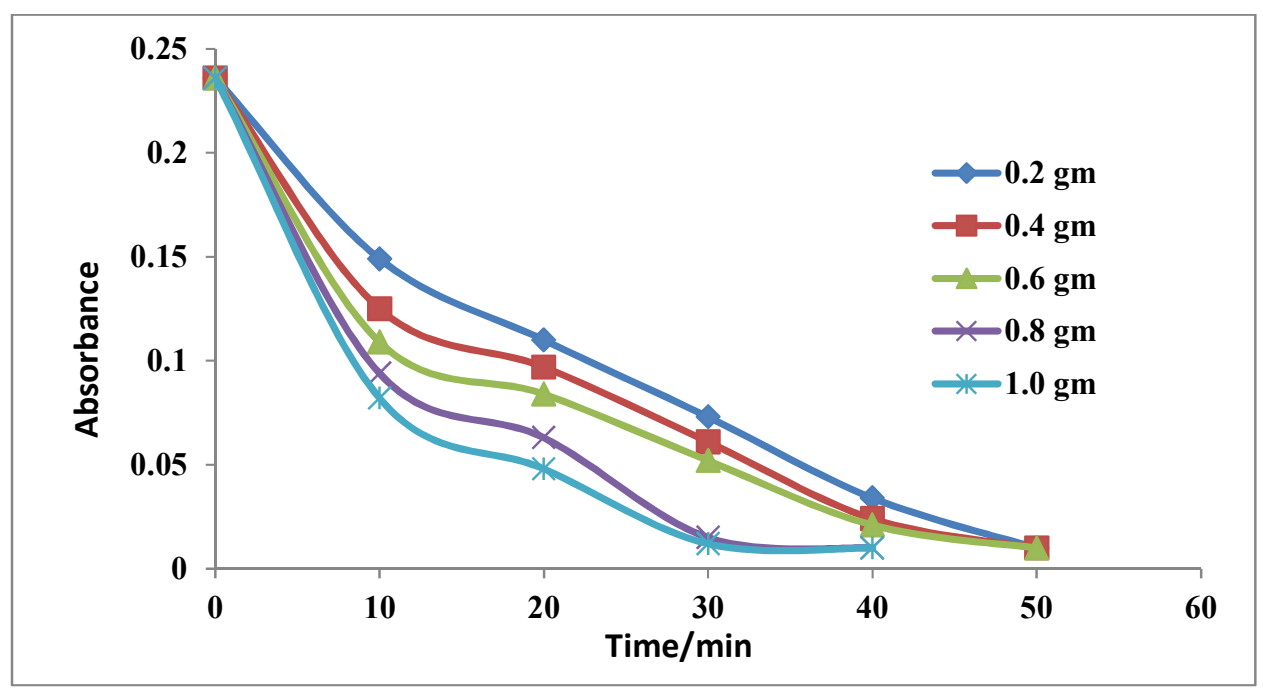

Fig. 8 Effect of amount of SCSHP on dye degradation 


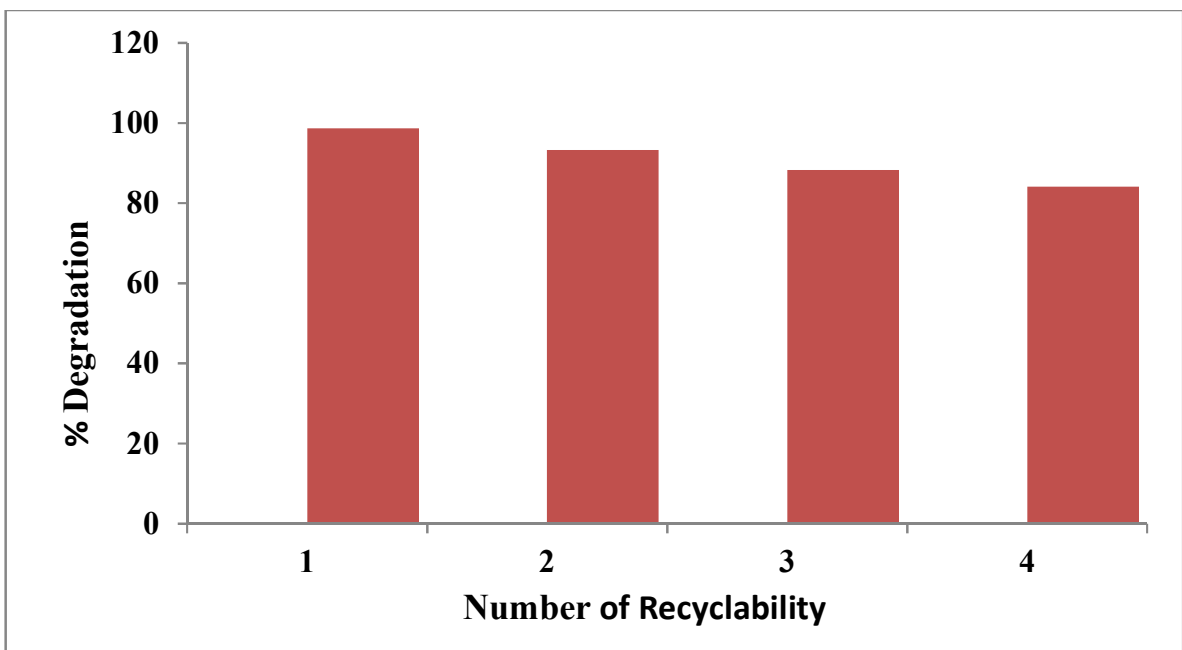

Fig. 9 Recyclability of SCSHP for degradation of Hydroxynaphthol blue dye.

\section{CONCLUSION}

Photocatalytic degradation of Hydroxynaphthol blue was investigated using SCSHP as a cost effective, efficient photocatalyst. Various parameters such as concentration of dye, amount of photocatalyst and recyclability were studied. This work investigated that photocatalysis is a very effective technology for the degradation of Hydroxynaphthol blue dye.

\section{REFERENCES}

[1] R. Ganesh, G.D. Boardman; Water Res. 28, 1367 (1994).

[2] A. Yadav, S. Neraliya, A. Gopesh; J. Env. Biol. 28, 159 (2007).

[3] A.V. Borhade, Y.R. Baste; J. Therm. Anal. Calorim. 107, 77 (2012).

[4] S. Chakrabarti, B.K. Datta; J. Hazard. Mat. 112, 269 (2004).
[5] Y. Xu, J. Jia, D. Zhang, Y. Wang; Chem. Engg. J. 150, 302 (2009).

[6] Y.S. Chen, J.C. Crittenden, S. Hackney, L. Sutter, D.W, Hand; Environ. Sci. Technol. 39, 1201 (2005).

[7] M. N. Rashad El, A.A. Amin; Int. J. Phy. Sci. 2, 73 (2007).

[8] A.D. Paola, E.G. Lopez, S. Ikeda, L. Palmisano; Catal. Today. 75, 87 (2002).

[9] M.A. Rauf, M.A. Meetani, S. Hisaindee; Desalination. 276, 13 (2011).

[10] V.A. Sakkas, A. Islam Md, C. Stalikas, T.A. Albanis; J. Hazard. Mat. 175, 33 (2010).

[11] A.V.Borhade, D. R. Tope and S.G. Gite, Arab. J. Chem., DOI.Org/10.1016/j.arabjc.2012.11 .001 . 
[12] A.V. Borhade, D.R. Tope, B.K. Uphade; Res. Chem. Intermed. 40, 211 (2012).

[13] A.V. Borhade, K.G. Kanade, D.R. Tope, M.D. Patil; Res. Chem. Intermed. DOI $10.1007 / \mathrm{s} 11164-$ 012-0515-z (2012).

[14] A.V. Borhade, Y. R. Baste; Arab. J. Chem. DOI.org.10.1016/ j. Arabic.2012.10.001.

[15] H. Liu, T. Peng, D. Ke, Z. Peng, C. Yan; Mater. Chem. Phys. 104, 377 (2007).

[16] S.M. Teleb, D.El. Sayed, E.M. Nour; Bull. Mater. Sci. 27, 483 (2004).
[17] M.S. Refat, AL-Qahatant; Bull Mater. Sci. 34, 853 (2011).

[18] S. Lee, K. Cho, Y. Son; Thin solid film. 524, 290 (2012).

[19] M. V. Nassar, I. S. Ahmed; Polyhedron. 30, 2431 (2011).

[20] A. V. Radha, A. Narrotsky, American Minerologist. 99, 1063 (2004).

[21] M. Mohamed, Al-Majthouba, S. Moamen, B. Refata; Adv. Appl. Sci. Res. 3, 183 (2012).

[22] I.K. Konstantinou, T.A. Albanis; Appl. Catal.B. Environ. 49, 1 (2004). 